\title{
Efficient Lambda Logic Based Optimisation Procedure to Solve the Large Scale Generator Constrained Economic Dispatch Problem
}

\author{
T. Adhinarayanan ${ }^{\dagger}$ and M. Sydulu*
}

\begin{abstract}
A simple and efficient Lambda logic ( $\lambda$-logic) based algorithm is proposed for the solution of the generator constrained economic dispatch problem when the generating units having prohibited zones. The proposed method solves the economic dispatch (ED) problem that takes into account ramprate limits, transmission losses and prohibited operating zones in the power system operation. The proposed method uses a simple heuristic rule based on average power of prohibited operating zones which produces the feasibility of solution for the restricted operating units. The effectiveness of the algorithm is tested on five different test systems and the performance compared with other relevant methods reported in the literature. In all the cases, the proposed algorithm performs better than the previous existing algorithms with a less computational burden.
\end{abstract}

Keywords: Economic Dispatch, Large Scale Power systems, average power of prohibited operating zones.

\section{Introduction}

Economic dispatch (ED) is the process of allocating the generation levels to the various generating units in the system so as to meet the load demand in the most economic way without violating any system or individual unit constraints. The importance of economic load dispatch is to get maximum usable power using minimum resources. The purpose of ED is to determine the optimal combination of power generations that minimizes the total generation cost while satisfying the constraints. It is difficult to solve the ED problem since the ED problem is a nonlinear, nonconvex, discrete optimization problem. However, good solutions of the ED problem would result in great economical benefits. In recent years, a lot of researches have been done and various mathematical programming optimization methods have been employed for solving ED problems. Many techniques such as the lambda iteration method, base point and participation method, and dynamic programming [1-3] have replaced obsolete techniques made as the best point loading and base load methods [1]. Although the most commonly used method in software is the lambda iteration [2] owing to its ease of implementation, its application to a large-scale model is not feasible due to oscillatory problems. Conventionally, the economic dispatch problem of a power system is solved in the environment of unit commitment and real time operation plants by assuming that each of the dispatchable on-line units can be regulated continuously between its minimum generation limit, $P_{i \min }$ and its maximum generation limit,

$\dagger \quad$ Corresponding Author : Dept. of Electrical Engineering, National Institute of Technology, Warangal (adhi_71@yahoo.co.in)

* Dept. of Electrical Engineering, National Institute of Technology, Warangal (sydulumaheswarapu@yahoo.co.in)

Received 25 February 2008; Accepted 6 July 2009
$P_{i \max }$. In practical systems, however some of the on-line units may have prohibited operating zones due to the physical limitations of power plant components such as vibrations in a shaft bearing in a certain operating region etc. For a unit with prohibited zones, its operating region, $\left[P_{i \min }, P_{i \max }\right]$, will be broken into several isolated subregions [4]. It can only be dispatched to one of the isolated sub-regions in practical operation.

The isolated sub-regions will form multiple decision spaces and result in a very challenging task for determining the optimal economic dispatch. Several methods have been proposed in the literature [4-16], to solve ED Problem considering transmission constraints and prohibited operating zones. This paper presents a simple and efficient algorithm based on ' $\lambda$-logic' for determining the optimal loading of generators having prohibited zones and ramp-rate limits, which uses a simple heuristic rule to determine the advantageous spaces. Recently, Meta-heuristic approaches that use Particle Swarm Optimisation (PSO) [8] and genetic algorithms (GAs) [9] have been successfully used in the solution of noncovex ED problems with prohibited zones. However, these approaches involve a large number of iterations and are sensitive to the parameter settings. The method proposed in [7-16] made the authors to work on large scale systems. Lin et al. [12] have presented an approach that integrates EP, tabu search and quadratic programming methods, the so-called (ETQ) method to solve the ED problem with prohibited operating zones. A. Pereira-Neto et al. [16] proposed Evolutionary strategy optimisation (ESO) method to solve the ED problem with nonconvex functions and consider nonlinear generator characteristics, such as ramprate limits and prohibited operating zones in the power system operation.

In this paper, a ' $\lambda$-logic' based approach is used to determine the optimal loading of generators having prohib- 
ited zones. This method requires only two iterations of ' $\lambda$ logic' based approach for small as well as for large scale ED problems without considering transmission losses and a few iterations when transmission losses considering in to view. The proposed method uses a simple heuristic rule based on average power of prohibited operating zones which produces the feasibility of solution for the restricted operating units. This work has been tested with five test case systems to show its feasibility and effectiveness for ED with Prohibited operating zones, ramp-rate limits, spinning reserve constraints and transmission losses.

\section{Problem Formulation}

The objective of ED problem is to determine the generation levels for all on-line units which minimize the total fuel cost, while satisfying a set of various constraints.

\subsection{Generation operation constraints}

In this study, the ramp-rate limits and prohibited operating zone constraints are considered.

A. Ramp-rate limit constraints: As mentioned in Section 1, the actual operating range of all on-line units is restricted by their corresponding ramp-rate limits. Fig. 1 shows three possible situations in which a unit is on-line from time interval $t-1$ to $t$ [9]. Fig. 3a shows the unit operating in steady-state conditions, Fig. $3 b$ shows the unit increasing its power generation whereas Fig. $3 \mathrm{c}$ shows the unit decreasing the power generation output

According to [9] and [14], the inequality constraints due to ramp-rate limits can be rewritten as:

- If generation increases:

$$
P_{i}^{t}-P_{i}^{t-1} \leq U R_{i}
$$

- If generation decreases:

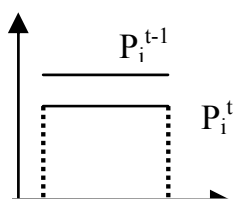

$\mathrm{t}-1$
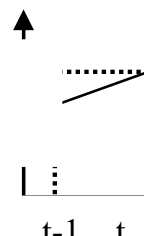

(b)

\section{4}

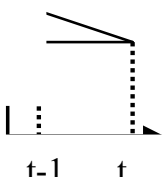

(c)

$$
P_{i}^{t-1}-P_{i}^{t} \leq D R_{i}
$$

Where $P_{i}^{t}$ is the present output power and $P_{i}^{t-1}$ is the previous output. $\quad U R_{i}$ is the up ramp-rate limit of the ith generator (in $\mathrm{MW} /$ time period). $D R_{i}$ is the down ramp-

Fig. 1. Three possible situations of an on-line generation unit
(a) Steady-state operation
(b) Increasing the level of power generation
(c) Decreasing the power output

rate limit of the ith generator (in MW/time period).

B. Prohibited operating zones: References [4], [9], and [14] have shown the input-output performance curve for a typical thermal unit with many valve points. These valve points generate many prohibited zones. In practical operation, adjusting the generation output $P_{i}^{t}$ of a unit must avoid unit operation in the prohibited zones.

\subsection{Problem formulation for ED problem with vari- ous constraints}

The objective is to minimize overall generation cost while satisfying load demand and all constraints. Considering this, the ED problem can be formulated as a constrained optimisation problem of the form

$$
\min : F_{T}=\sum_{i=1}^{n} F_{i}=\sum_{i=1}^{n} a_{i}+b_{i} P_{i}+c_{i} P_{i}^{2}
$$

This model is subject to follow constraints:

1. Power balance constraint:

$$
\sum_{i=1}^{n} P_{i}=P_{D}+P_{L}
$$

With

$$
P_{L}=\sum_{i=1}^{n} \sum_{j=1}^{n} P_{i} B_{i j} P_{j}+\sum_{i=1}^{n} B_{0 i} P_{i}+B_{00}
$$

2. Ramp-rate limits constraint:

$$
\max \left(P_{i}^{\min }, P_{i}^{t-1}-D R_{i}\right) \leq P_{i}^{t} \leq \min \left(P_{i}^{\max }, P_{i}^{t-1}+U R_{i}\right)
$$

3. Prohibited operating zones constraint:

$$
\begin{aligned}
& P_{i \min } \leq P_{i} \leq P_{i, 1}^{l} \\
& P_{i, j-1}^{u} \leq P_{i} \leq P_{i, j}^{l}, j=2,3, \ldots . m_{i} \\
& P_{i, m_{i}}^{u} \leq P_{i} \leq P_{i \max }
\end{aligned}
$$

4. Spinning reserve constraints:

$$
\sum_{i=1}^{n} S_{i} \geq S_{R}
$$

For set of on-line units without prohibited operating zones

$$
S_{i}=\min \left\{\left(P_{i \max }-P_{i}\right), S_{i \max }\right\}
$$

For set of on-line units with prohibited operating zones

$$
S_{i}=0
$$

where $n$ is the total number of generating units; $F_{T}$ is the total generation cost; $F_{i}$ is the power generation cost function of the ith unit; $a_{i}, b_{i}$ and $c_{i}$ are the cost coefficients of the ith generating unit; $P_{D}$ is the total demand; $P_{i}$ is real power output of the ith generating unit; $P_{i \min }$ and $P_{i \max }$ are the minimum and maximum power outputs of the ith generating unit, respectively; $P_{L}$ is the total transmission network loss as function of the unit power outputs and the Bmatrix coefficients (transmission loss 
matrix coefficients); $B_{i j}$ is the $i j^{\text {th }}$ element of the loss coefficient matrix, $B_{0 i}$ the $i^{\text {th }}$ element of the loss coefficient vector, $B_{00}$ is the loss coefficient constant, $m_{\mathrm{i}}$ is the number of prohibited zones of unit $i$; $j$ is the index of prohibited zones of a unit i; $P_{i, j}^{l / u}$ is the lower/upper bounds of the $j^{\text {th }}$ prohibited zone of unit $\mathrm{i}, \mathrm{S}_{\mathrm{i}}$ is the Spinning Reserve Contribution of unit $i, S_{R}$ is the System Spinning Reserve Requirement, and $\mathrm{S}_{\text {imax }}$ is the Maximum Spinning Reserve Contribution of Unit $i$.

\section{Solution Methodology}

\subsection{Proposed overall Algorithm for ED with Prohib- ited operating zones (considering transmission losses):}

The proposed method for ED consists of two executions of ' $\lambda$-logic' and the various steps involved in the proposed approach are outlined below.

Step 1: Read the input data $a_{i}, b_{i}, c_{i}, P_{i \min }, P_{i \max }, \mathrm{n}, U R_{i}$, $D R, P_{i}^{t-1}, m_{\mathrm{i}}, S_{\text {imax }}, P_{D}, B_{i j}, B_{0 i}, B_{00}$ and prohibited operating zone limits.

Step 2: Calculate the average power of unit prohibited zones $\left(P_{a v(i, j)}\right)$ for all the $m_{i}$ zones. This determines the exact advantageous space of prohibited operating zones (produced first time in literature).

$$
P_{a v(i, j)}=\frac{P_{i, j}^{l}+P_{i, j}^{u}}{2}
$$

Step 3: Solve the constrained ED problem without considering prohibited operating regions using ' $\lambda$-logic' based algorithm (First execution). If the real power output satisfies the constraints (4), (5), (6), (7) and (8) and prohibited operating zone limits, then optimum dispatch is obtained. Calculate the total generation cost and print the results else Go to step 4.

Step 4: check the unit which is having prohibited zone and the power limits of remaining units are fixed. If a unit $i$ falls in a zone $\mathrm{j}$, compare the output power of that unit with average power of prohibited operating zone $\left(P_{a v(i, j)}\right)$. If it falls below average power of prohibited operating zone choose the operating ranges of power between $\left(P_{i, j-1}^{u} \leq P_{i} \leq P_{i, j}^{l}\right)$ for that corresponding unit i. If it falls above average power of prohibited operating zone choose the operating ranges of power between $\left(P_{i, j}^{u} \leq P_{i} \leq P_{i, j+1}^{l}\right)$.

Step 5: After setting the inequality constraints of each unit as in step 4, Solve the constrained ED problem iteratively using ' $\lambda$-logic' based algorithm (second execution) and print the results. The obtained real output power of each unit is the optimal power output of each unit which satisfies the inequality constraints $(6,7)$, equality constraints (4), transmission loss constraints (5) and spinning reserve constraints (8).

Step 6: Calculate the Total generation cost $(\$ / \mathrm{h})$.

\subsection{Algorithmic steps involved in ' $\lambda$-logic' approach (without considering transmission losses)}

Step 1 Pre-prepared Power Demand data (PPD)

a) Calculate the Incremental cost of all known Power limits of each unit as follows

$$
\begin{aligned}
& \lambda_{\text {imin }}=\left(d F_{i} / d P_{i}\right) \text { at } P_{i}=P_{\text {imin }} \\
& \lambda_{\text {imax }}=\left(d F_{i} / d P_{i}\right) \text { at } P_{i}=P_{\text {imax }} \\
& \text { For } \mathrm{i}=1 \text { to } \mathrm{n} \text { units. }
\end{aligned}
$$

Where n- no. of units present in the system.

b) Arrange $\lambda$-vector in ascending order for all units

c) Now calculate total power demand for the known $\lambda_{\mathrm{J}}$ of the $\lambda_{\text {asc }}$ vector. For this, the following fundamental observation of ED condition is used.

$$
\begin{aligned}
& \text { If } P_{i}^{J}<\mathrm{P}_{\text {imin }} \text { then } P_{i}^{J}=\mathrm{P}_{\text {imin }} \\
& \text { If } P_{i}^{J}>\mathrm{P}_{\text {imax }} \text { then } P_{i}^{J}=\mathrm{P}_{\text {imax }} \\
& P_{i}^{J}=\left(\lambda_{J}-\alpha_{i}\right) /\left(\beta_{i}\right)
\end{aligned}
$$

Where $\mathrm{J}=1$ to $2 * \mathrm{n}$ units.

The calculations of $\mathrm{PPD}_{\mathrm{J}}$ are performed only once and tabulated against corresponding values of incremental fuel cost. This information can be treated as static system data and can be supplied as input data along with the coefficients of fuel cost functions. The steps $a, b, c$ completes the first step of the ' $\lambda$-logic' method. This part can be done offline and $\lambda_{\text {asc }}$ and PPD would remain as static data.

Step 2 Estimation of optimum generation for specified $P_{D}$

Say $\mathrm{P}_{\mathrm{D}}$ is system demand and look in to PPD if it is present in the PPD, then it is the optimal generation for the generating units. If it is not present in any of the $\mathrm{J}^{\text {th }}$ location, then Scan $\mathrm{PPD}_{\mathrm{J}}$ and identify the interval $\mathrm{J}$ and $\mathrm{J}+1$ corresponding to $\mathrm{P}_{\mathrm{D}}$.

Calculate $\lambda_{\text {final }}$ by using the following equations.

$$
\lambda_{\text {final }}=\lambda_{J}+\left(\frac{\left(\lambda_{J}-\lambda_{J+1}\right)\left(P_{D}-P P D_{J}\right)}{P P D_{J}-P P D_{J+1}}\right)
$$

and eq. (17) can be applied to find optimal generation incorporating $(14,15,16)$.

\subsection{Algorithmic steps involved in ' $\lambda$-logic' approach (Considering transmission losses)}

Step 1 Read all the input data.

Step 2 a) Calculate the Incremental cost of all known Power limits of each unit as follows

$$
\begin{aligned}
& \lambda_{\text {imin }}=\left(d F_{i} / d P_{i}\right) \text { at } P_{i}=P_{\text {imin }} \\
& \lambda_{\text {imax }}=\mathrm{p}^{*}\left(d F_{i} / d P_{i}\right) \text { at } P_{i}=P_{\text {imax }}
\end{aligned}
$$$$
\text { For } \mathrm{i}=1 \text { to } \mathrm{n} \text { units. }
$$

Where $\mathrm{n}$ is the no. of units present in the system 
$\mathrm{p}$ is the penalty factor, genrally considered as

1 and varies only when Power demand $\left(\mathrm{P}_{\mathrm{D}}\right)$ reaches towards $\mathrm{P}_{\mathrm{Dmax}}$ (Total of $P_{i}^{\max }$ ).

b) Arrange $\lambda$-vector in ascending order for all units and calculate total power demand for the known $\lambda_{\mathrm{J}}$ of the $\lambda_{\text {asc }}$ vector while incorporating eqns. (18) and eqns, (19).

$$
\left[\begin{array}{ccc}
\left(\frac{\beta_{1}}{\lambda_{J}}+2 B_{11}\right) & 2 B_{12} & 2 B_{1 n} \\
2 B_{n 1} & \left(\frac{\beta_{2}}{\lambda_{J}}+2 B_{22}\right) & \\
& & \left(\frac{\beta_{n}}{\lambda_{J}}+2 B_{n n}\right)
\end{array}\right]\left[\begin{array}{l}
P_{1}^{J} \\
P_{2}^{J} \\
P_{n}^{J}
\end{array}\right]=\left[\begin{array}{c}
1-B_{01}-\frac{\alpha_{1}}{\lambda_{J}} \\
1-B_{02}-\frac{\alpha_{2}}{\lambda_{J}} \\
1-B_{0 n}-\frac{\alpha_{n}}{\lambda_{J}}
\end{array}\right]
$$

If $P_{i}^{J}<\mathrm{P}_{\text {imin }}$ then use (14)

If $P_{i}^{J}>\mathrm{P}_{\text {imax }}$ then use (15)

If $P_{\text {imin }}<P_{i}^{J}<P_{\text {imax }}$ then $P_{i}^{J}$ is calculated value from (20).

The calculations of $\mathrm{PPD}_{\mathrm{J}}$ are performed only once and tabulated against corresponding values of incremental fuel cost. This information can be treated as static system data for the ED problem. It can be supplied as input data along with the coefficients of fuel cost functions. The steps $a, b, c$ completes the first step of the " $\lambda$-logic" method. This part can be done off-line and $\lambda_{\text {asc }}$ and $\mathrm{PPD}_{\mathrm{J}}=\sum_{i=1}^{n} P_{i}{ }^{J}-P_{L}{ }^{J}$ would remain as static data.

Step 3 Estimation of optimum generation for specified $P_{D}$

Say $\mathrm{P}_{\mathrm{D}}$ is system demand and look in to PPD if it is present in the PPD, then it is the optimal generation for the generating units. If it is not present in any of the $\mathrm{J}^{\text {th }}$ location, then Scan $\mathrm{PPD}_{\mathrm{J}}$ and identify the interval $\mathrm{J}$ and $\mathrm{J}+1$ corresponding to $\mathrm{P}_{\mathrm{D}}$.

Calculate $\lambda_{\text {new }}$ by using the following equations.

$$
\lambda_{\text {new }}^{\text {iter }}=\lambda_{J}+\left(\frac{\left(\lambda_{J}-\lambda_{J+1}\right)\left(P_{D}-P P D_{J}\right)}{P P D_{J}-P P D_{J+1}}\right)
$$

and use (22) to find optimal generation incorporating (14, 15 and 20).

Step 4 Calculate error $\varepsilon=\left|P_{\text {gen }}^{\text {iter }}-\left(P_{D}+P_{L}^{\text {iter }}\right)\right|$ where $P_{\text {gen }}^{i \text { ter }}=\sum_{i=1}^{n} P_{i}^{i \text { iter }}$ and $P_{L}^{i \text { ter }}=\sum_{i=1}^{n} \sum_{j=1}^{n} P_{i}^{i \text { er }} B_{i j} P_{j}^{i t e r}+\sum_{i=1}^{n} B_{0 i} P_{i}^{i \text { ter }}+B_{00}$ If $\varepsilon \leq 0.0001$ stop else repeat step 5 until the goal reaches.

Step 5 Calculate $\lambda_{\text {final }}$ by using

$$
\lambda_{\text {final }}=\lambda_{J}+\left(\frac{\left(\lambda_{J}-\lambda_{\text {new }}^{\text {iter }}\right)\left(P_{D}-\left(P_{\text {gen }}^{\text {iter }}-P_{L}^{\text {iter }}\right)\right.}{P P D_{J}-\left(P_{\text {gen }}^{\text {iter }}-P_{L}^{\text {iter }}\right)}\right)
$$

and use (22) to find optimal generation by incorporating (14, 15 and 20).

\section{NUMERICAL RESULTS}

This section presents the results of simulations on five test cases to validate the proposed method. The results are compared with other relevant methods in the literature to show its performance. The Algorithm has been coded in MATLAB Version 7.0 using a PC PENTIUM IV, $2.4 \mathrm{GHz}$ and $256 \mathrm{MB}$ RAM as the test platform.

\subsection{Description of the test cases:}

1. Case 1. The First test system [13] consist of 20 generating units, when transmission loss constraint is incorporated. This case has been compared with Lambda iteration method [14] and new Hopfield neural network [13].

2. Case 2. The second tests data [4] consist of two different 15 generating units, when all the constraints mentioned in Section 2 (except transmission losses and ramprate limits) are incorporated. This case has been compared with GA proposed in [12], an ETQ proposed in [12] and an ESO proposed in $[15,16]$.

3. Case 3. The third test data consist of a) six thermal units, 26 buses, and 46 transmission lines from [8] and b) 3 generating units from [7,9]. Both case a) and b) considers prohibited operating zones and ramp-rate limits. Case (a) has been compared with the PSO method proposed in [8], GA elitist search method in [8] and case (b) has been compared with GA [9] and 2-Phase neural network [7].

4. Case 4. The fourth test data consists of 15 thermal units from [4]. This case also considers prohibited operating zones and ramp-rate limits, as well as transmission network losses [8]. This case has been compared with the PSO method proposed in [8] and with a GA elitist search method in [8].

5. Case 5. The fifth test data consists of 40, 80, 120, 160 and 240 thermal units from [10]. In this case, prohibited operating zones and losses are released. This case has been compared with Classical Method [10] and PHN [10]. This case is tested with 40 units $[8,9]$ which consider prohibited operating zones and ramp-rate limits, as well as transmission network losses.

\subsection{Tests with case 1}

In this test, the proposed algorithm is compared with a conventional Lambda iteration method [13] and with a new Hopfield Neural Network [13]. To verify the effectiveness of the proposed approach, a twenty-unit test system is employed. This test system supplies a total load demand of $2500 \mathrm{MW}$. The fuel cost coefficients, generation limits for each unit and the loss formula coefficients of (5) are taken from [13]. The proposed method shown similar results to those of lambda-iteration method, new Hopfield Neural Network[13] and the proposed method are given in Table 1. Computational results from test case 1 confirm that the proposed method is more efficient than the methods available from [13]. Basically, the proposed method is computationally faster than the Lambda-iteration method.. However, 
the difference of CPU time required between these methods varies, because the computational requirement of the lambda-iteration method is related to its initial value of $\lambda$ guessed. The best generation cost reported until now is $62456.6341 \$ / \mathrm{h}$ [13] and losses are 91.9669MW [13]. The generation cost produced by the proposed method is opti$\mathrm{mal}$ as $62456.6333 \$ / \mathrm{h}$ and losses are $91.9666 \mathrm{MW}$.

Table 1. Comparison of three methods (Best solution) (Case 1)

\begin{tabular}{|c|c|c|c|}
\hline $\begin{array}{l}\text { Unit Power } \\
\text { output, MW }\end{array}$ & $\begin{array}{c}\text { Lambda-iteration } \\
\text { Method[13] }\end{array}$ & \begin{tabular}{|c|} 
New Hopfield Neural \\
Network[13]
\end{tabular} & $\begin{array}{c}\text { Proposed } \\
\text { method }\end{array}$ \\
\hline $\mathrm{P}_{1}$ & 512.7805 & 512.7804 & 512.78176 \\
\hline $\mathrm{P}_{2}$ & 169.1033 & 169.1035 & 169.10151 \\
\hline $\mathrm{P}_{3}$ & 126.8898 & 126.8897 & 126.89073 \\
\hline $\mathrm{P}_{4}$ & 102.8657 & 102.8656 & 102.86724 \\
\hline $\mathrm{P}_{5}$ & 113.6836 & 113.6836 & 113.6829 \\
\hline $\mathrm{P}_{6}$ & 73.5710 & 73.5709 & 73.572038 \\
\hline $\mathrm{P}_{7}$ & 115.2878 & 115.2876 & 115.29003 \\
\hline $\mathrm{P}_{8}$ & 116.3994 & 116.3994 & 116.39986 \\
\hline $\mathrm{P}_{9}$ & 100.4062 & 100.4063 & 100.4049 \\
\hline $\mathrm{P}_{10}$ & 106.0267 & 106.0267 & 106.02737 \\
\hline $\mathrm{P}_{11}$ & 150.2394 & 150.2395 & 150.23853 \\
\hline $\mathrm{P}_{12}$ & 292.7648 & 292.7647 & 292.76584 \\
\hline $\mathrm{P}_{13}$ & 119.1154 & 119.1155 & 119.11422 \\
\hline $\mathrm{P}_{14}$ & 30.8340 & 30.8342 & 30.831525 \\
\hline $\mathrm{P}_{15}$ & 115.8057 & 115.8056 & 115.80594 \\
\hline $\mathrm{P}_{16}$ & 36.2545 & 36.2545 & 36.254365 \\
\hline $\mathrm{P}_{17}$ & 66.8590 & 66.8590 & 66.859193 \\
\hline $\mathrm{P}_{18}$ & 87.9720 & 87.9720 & 87.971228 \\
\hline $\mathrm{P}_{19}$ & 100.8033 & 100.8033 & 100.80266 \\
\hline $\mathrm{P}_{20}$ & 54.3050 & 54.3050 & 54.304833 \\
\hline $\mathrm{P}_{\mathrm{L}},(\mathrm{MW})$ & 91.9670 & 91.9669 & 91.9666 \\
\hline $\begin{array}{l}\text { Total output } \\
\text { Power(MW) }\end{array}$ & 2591.9670 & 2591.967 & 2591.9666 \\
\hline Total $\operatorname{cost}(\$ / \mathrm{h})$ & 62456.6391 & 62456.6341 & 62456.6331 \\
\hline CPU time (sec) & 0.033757 & 0.006355 & 0.001255 \\
\hline
\end{tabular}

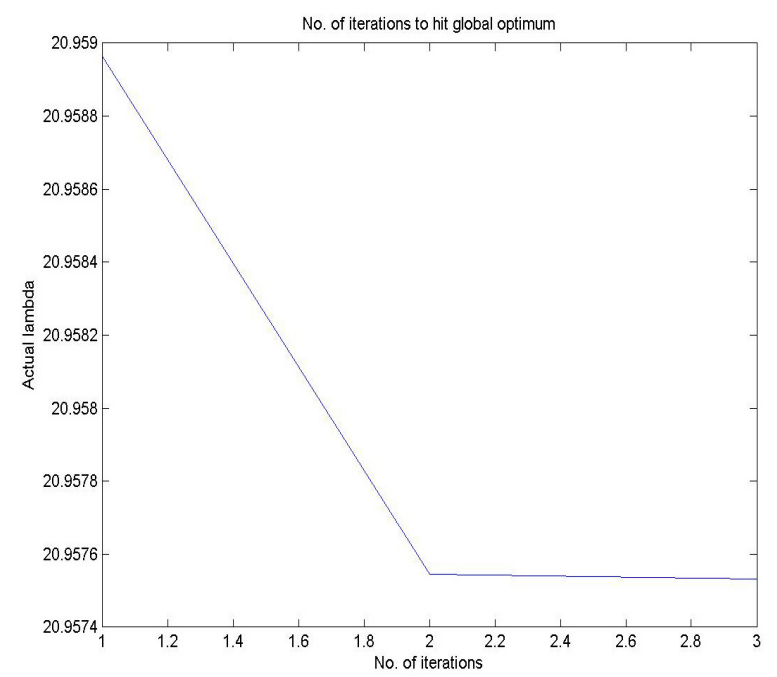

Fig. 2. Incremental cost $(\$ / M W h)$ Vs No. of iterations for 20 unit system

\subsection{Tests with case 2}

Case 2 considers a 15-unit system, in which four units (units 2, 5, 6 and 12) have prohibited operation zones, which are listed in Table II. Additional data can be found in [4]. The remaining 11 units will contribute with regulating reserves. This system supplies a 2650MW load demand with $200 \mathrm{MW}$ as spinning reserve.

Table 3 shows the average power of prohibited operating zones $\left(P_{a v(i, j)}\right)$ which is used first time in literature. $P_{a v(i, j)}$ helps to determine the advantageous enforcing limits in which optimal value of output power can be obtained.

Table 4 shows the performance comparison among the proposed algorithms, a GA approach [12], the ETQ method [12] and ESO method [15,16]. The proposed method performs better than the other methods in both the quality of the solution and the computational performance.

According to Table IV, it is observed that unit 2, unit 6 and unit 12 is in the fourth, fourth and second feasible operating regions respectively. Unit 5 is in prohibited operating zone 2. The output power of each unit in Table IV is calculated using Algorithm B under section III. Now apply the Algorithm A to set the new operating boundaries for all the units. Use (11)( i.e according to table III which has calculated by using (11)) to determine the operating regions of the units that consist of prohibited operating regions. According to average power of prohibited operating zone concept, limits of unit 2, 5, 6 and 12 are set to $4^{\text {th }}$, $2^{\text {nd }}, 4^{\text {th }}$ and $2^{\text {nd }}$ region respectively. According to these regions the operating limits are [450 455], [200 260], [455 $460]$ and [55 65] for unit 2, 5, 6 and 12 respectively. The power inequality constraints of remaining 11 units are same. But the reference [12], [15] and [16] has taken the upper operating ranges (i.e from [335 390] instead of [200 260]) which leads to the optimal power combination of units by using proposed algorithm. Thus the proposed method uses (11) to provide optimal feasible region which has been followed in all test cases.

Table 2. Prohibited operating zones (case 2)

\begin{tabular}{c|c|c|c|c}
\hline Unit & No. of zones & Zone1(MW) & Zone2(MW) & Zone3(MW) \\
\hline 2 & 3 & {$[185,225]$} & {$[305,335]$} & {$[420,450]$} \\
\hline 5 & 3 & {$[180,200]$} & {$[260,335]$} & {$[390,420]$} \\
\hline 6 & 3 & {$[230,255]$} & {$[365,395]$} & {$[430,455]$} \\
\hline 12 & 2 & {$[30,55]$} & {$[65,75]$} & \\
\hline
\end{tabular}

Table 3. Average power of Prohibited operating zones (case 2)

\begin{tabular}{c|c|c|c|c}
\hline Unit & No. of zones & Zone1(MW) & Zone2(MW) & Zone3(MW) \\
\hline 2 & 3 & 205.0 & 320.0 & 435.0 \\
\hline 5 & 3 & 190.0 & 297.5 & 405.0 \\
\hline 6 & 3 & 242.5 & 380.0 & 442.5 \\
\hline 12 & 2 & 42.5 & 70.0 & \\
\hline
\end{tabular}


Table 4. Comparison of propose d algorithm

\begin{tabular}{c|c|c}
\hline $\begin{array}{c}\text { Unit } \\
\text { Power } \\
\text { output, } \\
\text { MW }\end{array}$ & $\begin{array}{c}\text { Proposed method } \\
\text { (without considering } \\
\text { Prohibited operating } \\
\text { zones) }\end{array}$ & $\begin{array}{c}\text { Proposed method } \\
\text { (Considering prohibited } \\
\text { operating zones) }\end{array}$ \\
\hline $\mathrm{P}_{1}$ & 455.0 & 455.00 \\
\hline $\mathrm{P}_{2}$ & 455.0 & 455.00 \\
\hline $\mathrm{P}_{3}$ & 130.0 & 130.00 \\
\hline $\mathrm{P}_{4}$ & 130.0 & 130.00 \\
\hline $\mathrm{P}_{5}$ & 295.2988 & 260.00 \\
\hline $\mathrm{P}_{6}$ & 460.00 & 460.00 \\
\hline $\mathrm{P}_{7}$ & 465.00 & 465.00 \\
\hline $\mathrm{P}_{8}$ & 60.00 & 60.00 \\
\hline $\mathrm{P}_{9}$ & 25.00 & 25.00 \\
\hline $\mathrm{P}_{10}$ & 20.00 & 20.00 \\
\hline $\mathrm{P}_{11}$ & 43.3731 & 70.00 \\
\hline $\mathrm{P}_{12}$ & 56.3279 & 65.00 \\
\hline $\mathrm{P}_{13}$ & 25.00 & 25.00 \\
\hline $\mathrm{P}_{14}$ & 15.00 & 15.00 \\
\hline $\mathrm{P}_{15}$ & 15.00 & 15.00 \\
\hline $\begin{array}{c}\text { Total output } \\
\text { Power(MW) }\end{array}$ & 2650.00 & 2650.00 \\
\hline Total cost(\$/h) & 32502.97 & 32506.18 \\
\hline Mean Computation & 0.0170 & 0.0320 \\
\hline Time(s) & &
\end{tabular}

Table 5 shows the performance comparison among the proposed algorithms, a GA approach [12], the ETQ method [12] and ESO method [15,16]. The proposed method performs better than the other methods in both the quality of the solution and the computational performance. The total generation cost using the proposed method reduced about $8.82 \$ / \mathrm{h}, 1.32 \$ / \mathrm{h}$ and $1.49 \$ / \mathrm{h}$ when compared with GA method, ETQ and ESO method respectively.

Table 5. Comparison of three methods (Best solution) (Case 2)

\begin{tabular}{c|c|c|c|c}
\hline $\begin{array}{c}\text { Unit } \\
\text { Power } \\
\text { output, } \\
\text { MW }\end{array}$ & $\begin{array}{c}\text { GA } \\
{[12]}\end{array}$ & $\begin{array}{c}\text { ETQ } \\
{[12]}\end{array}$ & $\begin{array}{c}\text { ESO } \\
{[16]}\end{array}$ & Proposed method \\
\hline $\mathrm{P}_{1}$ & 406.1 & 450.0 & 449.953 & 455.00 \\
\hline $\mathrm{P}_{2}$ & 453.8 & 450.0 & 450.054 & 455.00 \\
\hline $\mathrm{P}_{3}$ & 130.0 & 130.0 & 130.000 & 130.00 \\
\hline $\mathrm{P}_{4}$ & 130.0 & 130.0 & 130.000 & 130.00 \\
\hline $\mathrm{P}_{5}$ & 355.0 & 335.0 & 335.137 & 260.00 \\
\hline $\mathrm{P}_{6}$ & 456.8 & 455.0 & 455.393 & 460.00 \\
\hline $\mathrm{P}_{7}$ & 459.8 & 465.0 & 464.376 & 465.00 \\
\hline $\mathrm{P}_{8}$ & 60.0 & 60.0 & 60.013 & 60.00 \\
\hline $\mathrm{P}_{9}$ & 26.6 & 25.0 & 25.010 & 25.00 \\
\hline $\mathrm{P}_{10}$ & 21.6 & 20.0 & 20.000 & 20.00 \\
\hline $\mathrm{P}_{11}$ & 36.2 & 20.0 & 20.000 & 70.00 \\
\hline $\mathrm{P}_{12}$ & 59.0 & 55.0 & 55.059 & 65.00 \\
\hline $\mathrm{P}_{13}$ & 25.0 & 25.0 & 25.000 & 25.00 \\
\hline $\mathrm{P}_{14}$ & 15.0 & 15.0 & 15.000 & 15.00 \\
\hline $\mathrm{P}_{15}$ & 15.0 & 15.0 & 15.000 & 15.00 \\
\hline $\begin{array}{c}\text { Total output } \\
\text { Power(MW) }\end{array}$ & 2649.9 & 2650 & 2649.995 & 2650.00 \\
\hline $\begin{array}{c}\text { Total cost}(\$ / h) \\
\text { Mean Computa- } \\
\text { tion Time } \\
(\mathrm{s})\end{array}$ & 32515.00 & 32507.50 & 32507.67 & 32506.18 \\
\hline & 398.5 & 15.8 & 13.8 & 0.0320 \\
\hline & & & & \\
\hline
\end{tabular}

\subsection{Tests with case 3}

Case 3 a) considers a six-unit system in which all units are within the prohibited operating zones and ramp-rate limits. This system supplies a $1263 \mathrm{MWload}$ demand. The data for the individual units and the $B$ matrix of the transmission loss coefficient (with a 100MVA base capacity) are taken from [8].

Table 6 is a comparison of the best solutions obtained with the proposed method, PSO and GA methods, respectively. Notice that all methods obey the system constraints, such as ramp-rate limits and prohibited zones. Fig. 3 shows the number of iterations to hit global optimum for 6 units system.

Case 3 b) considers a 3-unit system in which all units are within the prohibited operating zones and ramp-rate limits. This system supplies a $300 \mathrm{MW}$ load demand. The data for the individual units and their constraints are taken from [7,9]. Table VI is a comparison of the best solutions obtained with the proposed method, 2-Phase neural network and GA methods, respectively.

Table 6. Comparison of three methods (Best solution) (Case 3 (a))

\begin{tabular}{c|c|c|c}
\hline $\begin{array}{c}\text { Unit Power } \\
\text { output, MW }\end{array}$ & $\begin{array}{c}\text { PSO } \\
{[8]}\end{array}$ & $\begin{array}{c}\text { GA } \\
{[8]}\end{array}$ & Proposed method \\
\hline $\mathrm{P}_{1}$ & 447.95 & 474.81 & 447.5076 \\
\hline $\mathrm{P}_{2}$ & 173.32 & 178.64 & 173.3159 \\
\hline $\mathrm{P}_{3}$ & 263.47 & 262.21 & 263.4605 \\
\hline $\mathrm{P}_{4}$ & 139.06 & 134.28 & 139.0629 \\
\hline $\mathrm{P}_{5}$ & 165.47 & 151.90 & 165.4711 \\
\hline $\mathrm{P}_{6}$ & 87.13 & 74.18 & 87.13244 \\
\hline $\mathrm{P}_{\mathrm{L}},(\mathrm{MW})$ & 12.96 & 13.02 & 12.95 \\
\hline $\begin{array}{c}\text { Total output } \\
\text { Power(MW) }\end{array}$ & 1275.96 & 1276.03 & 1275.95 \\
\hline Total cost(\$/h) & 15450.000 & 15459.0 & 15449.796 \\
\hline $\begin{array}{c}\text { Average CPU time } \\
(\mathrm{sec})\end{array}$ & 14.86 & 41.58 & 0.04687 \\
\hline
\end{tabular}

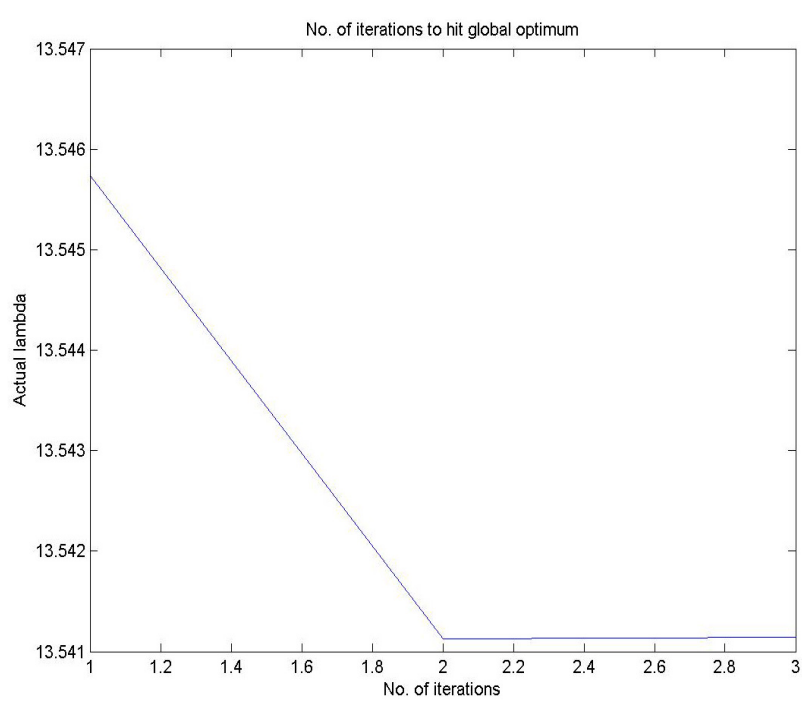

Fig. 3. Incremental cost (\$/Mwh) Vs No. of iterations for 6 units system 
Table 7. Comparison of two methods (Best solution) (case3 (b))

\begin{tabular}{c|c|c|c}
\hline $\begin{array}{c}\text { Unit Power } \\
\text { output, MW }\end{array}$ & GA [9] & $\begin{array}{c}\text { 2-Phase neural } \\
\text { network[7] }\end{array}$ & Proposed Method \\
\hline $\mathrm{P}_{1}$ & 194.26 & 165.00 & 198.436 \\
\hline $\mathrm{P}_{2}$ & 50.00 & 113.40 & 80.362 \\
\hline $\mathrm{P}_{3}$ & 79.62 & 34.00 & 34.000 \\
\hline $\mathrm{P}_{\mathrm{L}},(\mathrm{MW})$ & 24.01 & 12.45 & 12.798 \\
\hline $\begin{array}{c}\text { Total output } \\
\text { Power(MW) }\end{array}$ & 323.89 & 312.45 & 312.798 \\
\hline Total cost $(\$ / \mathrm{h})$ & 3737.20 & 3652.60 & 3634.874 \\
\hline
\end{tabular}

From Table 7, it is observed that the optimal generation cost is obtained by the proposed method as $3634.874 \$ / \mathrm{h}$. The total generation cost using the proposed method reduced about 102.326 $\$ / \mathrm{h}$ and $17.726 \$ / \mathrm{h}$ when compared with GA method and 2-Phase neural network method respectively.

From Table 7, it is observed that the optimal generation cost is obtained by the proposed method as $3634.874 \$ / \mathrm{h}$. The total generation cost using the proposed method reduced about 102.326 $\$ / \mathrm{h}$ and $17.726 \$ / \mathrm{h}$ when compared with GA method and 2-Phase neural network method respectively.

\subsection{Tests with case 4}

Case 5 considers a 15 -unit system $[4,8]$ in which all the units obey the prohibited operating zones and ramp-rate limits. This system supplies $2630 \mathrm{MW}$ load demand. The characteristics of this case and the respective $B$ transmission loss coefficients matrix are taken from [8].

Table 8. Comparison of three methods (Best solution) (Case 4)

\begin{tabular}{c|c|c|c}
\hline $\begin{array}{c}\text { Unit Power } \\
\text { output, MW }\end{array}$ & $\begin{array}{c}\text { PSO } \\
{[8]}\end{array}$ & $\begin{array}{c}\text { GA } \\
{[8]}\end{array}$ & Proposed method \\
\hline $\mathrm{P}_{1}$ & 439.12 & 415.31 & 455.0000 \\
\hline $\mathrm{P}_{2}$ & 407.97 & 359.72 & 380.0000 \\
\hline $\mathrm{P}_{3}$ & 119.63 & 104.42 & 130.0000 \\
\hline $\mathrm{P}_{4}$ & 129.99 & 74.98 & 130.0000 \\
\hline $\mathrm{P}_{5}$ & 151.07 & 380.28 & 170.0000 \\
\hline $\mathrm{P}_{6}$ & 459.99 & 426.79 & 460.0000 \\
\hline $\mathrm{P}_{7}$ & 425.56 & 341.32 & 430.0000 \\
\hline $\mathrm{P}_{8}$ & 98.56 & 124.79 & 60.0000 \\
\hline $\mathrm{P}_{9}$ & 113.49 & 133.14 & 56.87547 \\
\hline $\mathrm{P}_{10}$ & 101.11 & 89.26 & 160.0000 \\
\hline $\mathrm{P}_{11}$ & 33.91 & 60.06 & 80.0000 \\
\hline $\mathrm{P}_{12}$ & 79.96 & 50.00 & 80.0000 \\
\hline $\mathrm{P}_{13}$ & 25.00 & 38.77 & 25.0000 \\
\hline $\mathrm{P}_{14}$ & 41.41 & 41.94 & 15.0000 \\
\hline $\mathrm{P}_{15}$ & 35.61 & 22.64 & 28.07365 \\
\hline $\mathrm{P}_{\mathrm{L}},(\mathrm{MW})$ & 32.42 & 38.28 & 29.9491 \\
\hline $\begin{array}{c}\text { Total output } \\
\text { Power(MW) }\end{array}$ & 2662.41 & 2668.44 & 2659.9491 \\
\hline Total cost(\$/h) & 32858.00 & 33113.00 & 32713.9510 \\
\hline $\begin{array}{c}\text { Average CPU } \\
\text { time }(\mathrm{sec})\end{array}$ & 26.59 & 49.31 & 0.016 \\
\hline & & & \\
\hline & & & \\
\hline & & & \\
\hline
\end{tabular}

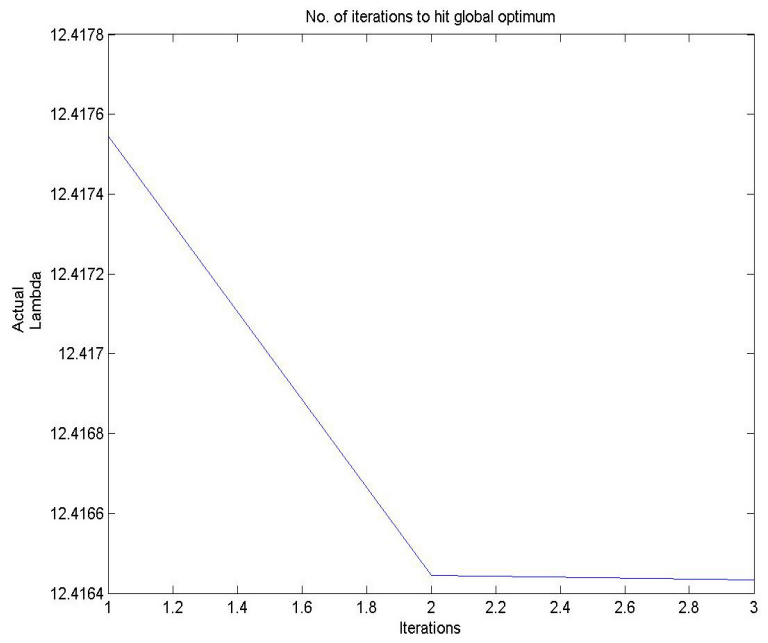

Fig. 4. Incremental cost $(\$ / \mathrm{Mwh}) \mathrm{Vs}$ No. of iterations for 15 units system

Table 8 compares the best solution of the proposed methods, PSO and GA, respectively. Table VIII lists the comparative performances for the generation cost and average CPU times. The total generation cost using the proposed method reduced about 144.049 \$/h and 399.049 \$/h when compared with PSO method and GA method respectively. Figure 4 shows how the Optimal Incremental Cost reaches iterations.

\subsection{Tests with case 5}

Case 5 considers five larger test systems are taken from [10]. In this tests, the system consists of 40 units in the realistic Taipower system that is large-scale and mixed generating system where coal-fired, oil-fired, gas-fired, diesel, and combined cycle are all present [10]. The load demand of the system is $9500 \mathrm{MW}$. The larger test systems 80, 120, 160 and 240 units have been created simply by expanding the 40 unit system. The load demand of the remaining test systems are $200000 \mathrm{MW}, 31500 \mathrm{MW}, 41000$ MW and 57000 MW for the 80, 120, 160 and 240 unit systems respectively. In Table 8 , this case releases the transmission losses in order to demonstrate the efficiency of the proposed approach. In Table 9, it is tested with 40 units which consider prohibited operating zones and ramp-rate limits, as well as transmission network losses. Due to lack of B loss coefficient data, the B loss coefficients matrix is generated randomly. The load demand of the system is $8550 \mathrm{MW}$.

Table 9. Comparison of three methods (Best solution) (Case 5)

\begin{tabular}{c|c|c|c|c}
\hline \multirow{2}{*}{ No. of units } & \multirow{2}{*}{$\begin{array}{c}\text { Load } \\
(\mathrm{GW})\end{array}$} & \multicolumn{3}{|c}{ Total cost $(\mathrm{k} \$ \mathrm{~h})$} \\
\cline { 3 - 5 } & & $\mathrm{CM}[10]$ & PHN[10] & Proposed Method \\
\hline 40 & 9.5 & 128.4 & 129.1 & 128.4 \\
\hline 80 & 20.0 & 271.9 & 272.8 & 271.9 \\
\hline 120 & 31.5 & 431.7 & 432.6 & 431.7 \\
\hline 160 & 41.0 & 559.5 & 560.7 & 559.6 \\
\hline 240 & 57.0 & 770.55 & 774.98 & 770.54 \\
\hline
\end{tabular}


Table 9 compares best solution of the proposed methods, classical method (CM) and PHN, respectively. From the Table 9, it is observed that the proposed method outperforms the PHN in all cases and it produces the optimal generation cost as similar to CM in all cases. From Table 10 , it is observed that, the proposed method produces the feasible and optimal generation for large size systems even when Prohibited operating zones and transmission losses are considered. The optimal generation cost obtained is 129777.531620 \$/h with losses 87.403674 MW.

\section{G. Global Comments}

The test results show that Proposed ' $\lambda$-logic' performs well, either matching or performing better than many of the previously reported methods. In test case 1 , it matches with the Hopfield neural network with slighter reduction in generation cost. The proposed method takes just two itertions to reach the optimal cost for case 1 . In test case 2 to case 4 , it performs slightly better than the previously reported methods such as 2- Phase neural netwotk, PSO, GA, ETQ and ESO by converging in 2 to 3 iterations. In test case 5, it performs better than the Hopfield neural network and matches with the classical method. It takes single iteration to converge when the transmission losses are neglected. Due to the proposed heuristic rule (Average power of prohibited operating zone), it finds the single advantageous space within single iteration. The solution for large size ED problem obtained without any convergence problem even when all the constraints are included.

Table 10. Optimised generation dispatch for 40-units problem with prohibited zones and transmission losses (case 5)

\begin{tabular}{|c|c|c|c|c|c|c|c|}
\hline Unit & 1 & 2 & 3 & 4 & 5 & 6 & 7 \\
\hline $\begin{array}{l}\text { Output } \\
\text { power } \\
(\mathrm{MW})\end{array}$ & 80 & 80 & 190 & 42 & 42 & 115 & 165 \\
\hline Unit & 8 & 9 & 10 & 11 & 12 & 13 & 14 \\
\hline $\begin{array}{l}\text { Output } \\
\text { power } \\
(\mathrm{MW}) \\
\end{array}$ & 217 & 265 & 165 & 355 & 355 & 230 & 280 \\
\hline Unit & 15 & 16 & 17 & 18 & 19 & 20 & 21 \\
\hline $\begin{array}{l}\text { Output } \\
\text { power } \\
(\mathrm{MW})\end{array}$ & 270 & 270 & 270 & 470 & 470 & 468 & 468 \\
\hline Unit & 22 & 23 & 24 & 25 & 26 & 27 & 28 \\
\hline $\begin{array}{l}\text { Output } \\
\text { power } \\
\text { (MW) }\end{array}$ & 460 & 460 & 460 & 460 & 460 & 460 & 35.58 \\
\hline Unit & 29 & 30 & 31 & 32 & 33 & 34 & 35 \\
\hline $\begin{array}{l}\text { Output } \\
\text { power } \\
(\mathrm{MW}) \\
\end{array}$ & 35.48 & 35.46 & 54.62 & 54.57 & 57.27 & 52.26 & 38.25 \\
\hline Unit & 36 & 37 & 38 & 39 & 40 & & \\
\hline $\begin{array}{l}\text { Output } \\
\text { power } \\
\text { (MW) }\end{array}$ & 47.25 & 48.96 & 50.36 & 50.16 & 50.11 & & \\
\hline
\end{tabular}

\section{Conclusions}

This paper presents an efficient and effective approach for solving the economic dispatch problem when the online generating units have prohibited operating zones. The proposed approach offers two execution of $\lambda$-logic method, which offers a best contribution in the area of economic dispatch. The proposed method uses a simple heuristic rule based on average power of prohibited operating zones which produces the feasibility of solution for the restricted operating units. In contrast to other conventional methods, this approach gives a promising value of power for providing improved economic dispatch. It reduces the computational burden and is superior to many of available techniques of economic dispatch. In most of the cases, the proposed algorithm outperforms other approaches reported in the literature, in that it provides higher-quality solutions with less computational burden. The method yields a good near-optimal solution for large scale systems without any convergence problems for convex functions which has been illustrated through numerical testing and a comparative analysis. This $\lambda$-logic method may be suggested for the solution for ED problems for on-line applications when the on-line units having prohibited zones.

\section{References}

[1] B.H.Chowdhury, and S. Rahman, 'A review of recent advances in economic dispatch', IEEE Trans. Power Syst., pp. 1248-1259, 1990.

[2] A.J Wood, and B.F. Wollenberg, "Power generation, operation, and control," 2nd ed., John Wiley and sons, 1996.

[3] R.J. Ringlee, and D.D. Williams, 'Economic dispatch operation considering valve throttling losses, II - distribution of system loads by the method of dynamic programming', IEEE Trans. Power Appar. Syst., 82, (1), 1963.

[4] F.N., Lee, and A.M. Breipohl, "Reserve constrained economic dispatch with prohibited zones," IEEE Trans. Power Syst., vol. 8, (1) pp. 246-254, 1993.

[5] J.Y Fan,., and J.D McDonald,.: “A practical approach to real time economic dispatch considering unit's prohibited zones," IEEE Trans. Power Syst. 9, (4), pp. 1737-1743, 1994.

[6] S.O.Orero, and M.R Irving.: 'Economic dispatch of generators with prohibited operating zones: A genetic algorithm approach', IEE Proc., Gener., Trans. Distrib., 143, (6), pp. 529-533, 1996.

[7] R. Naresh, J. Dubey, and J. Sharma, "Two-phase neural network based modeling framework of constrained economic load dispatch," IEE Proc.-Gener. Trans., Distrib., 151, (3), pp. 373-378, 2004.

[8] Z.L. Gaing, 'Particle swarm optimization to solving the economic dispatch considering the generator constraints', IEEE Trans. Power Syst., 18, (3), pp. $1187-$ 1195, 2003. 
[9] P.-H Chen, and H.-C Chang, 'Large-scale economic dispatch by genetic algorithm', IEEE Trans. Power Syst., 10, (4), pp. 1919-1926, 1995.

[10] T.Yalcinoz, and M.J. Short, 'Large-scale economic dispatch using an improved Hopfield neural network', IEE Proc., Gener., Transm. Distrib., 144, (2), pp. 181-185, 1997.

[11] K.P. Wong,., and Y.W. Wong, 'Genetic and generic/simulated annealing approaches to economic dispatch', IEE Proc., Gener. Transm. Distrib., 141, pp. 507-513, 1994.

[12] W.M Lin, F.S.Cheng, and M.T. Tsay, 'Nonconvex economic dispatch by integrated artificial intelligence', IEEE Trans. Power Syst., 16, (2), pp. 307-311, 2001.

[13] T. Su, and C. T.Lin, 'New approach with Hopfield modeling framework to economic dispatch', IEEE Trans. Power Syst., 15, (2), pp. 541-545, 2000.

[14] T. Su, and G.J.Chiou, 'A fast computation Hopfield method to economic dispatch of power systems', IEEE Trans. Power Syst., 12, (4), pp. 1759-1764, 1997.

[15] A. Pereira-Neto, C. Unsihuay, and O.R. Saavedra, 'Efficient evolutionary strategy optimisation procedure to solve the nonconvex economic dispatch problem with generator constraints', IEE Proc., Gener. Transm. Distrib., 152, (5) pp. 653-660, 2005.

[16] A. Pereira-Neto,C. Unsihuay, and O.R. Saavedra, 'Efficient evolutionary strategy optimisation procedure to solve the nonconvex economic dispatch problem with generator constraints', IET Gener.Transm. Distrib., 1, (2), pp. 366-368, 2007.

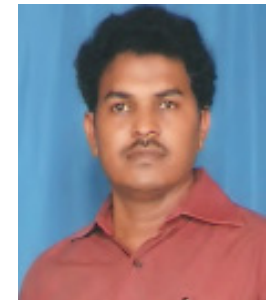

T.Adhinarayanan received the B.E. degree in Electrical and Electronics Engineering at Arunai Engineering College, Tiruvannamalai, India, in 2002 and M.E degree in Power systems engineering at Crescent Engineering College, Chennai, India, in 2004. He is currently pursuing the Ph.D Degree in the Department of Electrical Engineering, National Institute of Technology, Warangal, India. His Research interests include Power system operation and control, Metaheuristic Applications to Power systems.

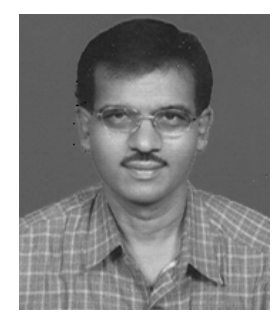

Maheswarapu Sydulu obtained his B.Tech (Electrical Engineering,1978), M.Tech (Power Systems,1980), Ph.D (Electrical Engineering - Power Systems,1993), all degrees from Regional Engineering College, Warangal, Andhra Pradesh, INDIA. His areas of interest include Real Time power system operation and control, ANN, fuzzy logic and Genetic Algorithm applications in Power Systems, Distribution system studies, Economic operation, Reactive power planning and management. Presently he is working as Professor and Head of Electrical Engineering Department, National Institute of Technology, Warangal (formerly RECW) 